ELORE (ISSN 1456-3010), vol. $16-1 / 2009$.

Julkaisija: Suomen Kansantietouden Tutkijain Seura ry.

[http://www.elore.fi/arkisto/1_09/ajank_paaskoski_01_09.pdf]

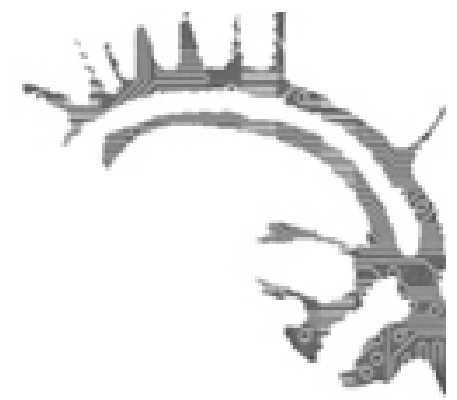

\title{
Ajankohtaista:
}

\section{KANSATIETEEN HEIMOKULTTUURI}

Lectio praecursoria Helsingin yliopistossa 6.6.2008

\section{$\underline{\text { Leena Paaskoski }}$}

Ryhtyessäni vuonna 2004 kirjoittamaan metsänhoitajuutta käsittelevää kansatieteen väitöskirjaani huomasin varsin pian tutkivani yhtä aikaa kahta ammattiryhmää, metsänhoitajia ja kansatieteilijöitä. Tutkimuskysymykseni mitä on metsänhoitajuus edellytti kysymyksiä mitä on kansatiede ja mitä on olla kansatieteilijä. Miten kansatieteilijä valitsee näkökulmansa ja miten hän tieteenalansa edustajana kirjoittaa metsänhoitajista? Refleksiivisen tutkimusotteen perusteena on vuorovaikutus tutkijan ja tutkittavien välillä (esim. Fingerroos \& Haanpää 2006, 41-43), ja siinä puolestaan on kysymys paitsi tutkimuskohteensa tuntemisesta myös itsetuntemuksesta.

Metsänhoitajakuntaan liittyminen ja metsänhoitajan ammatissa toimiminen ovat edellyttäneet ammattikunnan jäseniltä sen perinteiden, tapojen, käytäntöjen ja arvojen omaksumista, eräänlaisen metsänhoitajuuden kieliopin oppimista. Tämä oppimisen ja sosiaalistumisen prosessi on tapahtunut opiskeluaikana ja vahvistunut edelleen ammatissa toimiessa. Metsänhoitajuuden kokemuksia on jaettu ammattikunnan jäsenten kesken metsäylioppilaiden ja metsänhoitajien keskinäisessä vuorovaikutuksessa sekä metsänhoitajapolvien välillä. Tällaista omaan ammattiryhmään tai tieteenalaan liittymistä Oili-Helena Ylijoki on sosiaalitieteellisessä tutkimuksessaan kuvannut heimo-metaforalla. Jokaisella tieteenalalla on oma heimokulttuurinsa, johon opiskelijanoviisit opiskelunsa kuluessa sosiaalistuvat omaksumalla heimonsa traditiot, arvot ja toimintatavat. Vasta heimokulttuurin sisäistäminen ja sen pelisääntöjen oppiminen mahdollistavat heimon täysivaltaisen jäsenyyden saavuttamisen. (Ylijoki 2004.)

\section{KANSATIETEELLINEN NÄKÖKULMA?}

Voidakseen kirjoittaa kansatieteellistä tutkimusta - tässä tapauksessa metsänhoitajista myös kansatieteilijän on siis tunnettava ja hallittava oman tieteenalansa perinteet, tavat 


\section{KanSATIETEEN heimoKULtTUURI}

ja ominaispiirteet. Tieteenalan - edes oman tieteenalan - tunnusmerkkien määrittely ei kuitenkaan aina ole yksinkertaista, eivätkä määritelmät ole pysyviä. Kun syksyllä 1986 tulin Helsingin yliopistoon opiskelemaan, kansatiede oli minulle aivan uusi ja ennestään tuntematon oppiaine. Olin kuitenkin pääsykokeisiin valmistautuessani oppinut, että kansatiede tutki aineellista kansankulttuuria, kun taas naapuritieteelle, silloiselle kansanrunoudentutkimukselle, kuului kansankulttuurin henkinen puoli. Kansatieteen opinnäytetyöni 1980-1990-luvun taitteessa käsittelivätkin työväen ja maaseudun ammatteja ja työpaikkoja: pientä helsinkiläisleipomoa ja pohjoispohjalaisen maaseudun marjanjalostustehdasta. Kansatieteen kansaahan olivat jo pitkään olleet talonpoikaisväestön ohella myös kaupunkilaiset ja työväestö. Molemmissa opinnäytetöissäni kiinnitin huomioni niin ikään oppiaineeni perinteiden mukaisesti työmenetelmiin ja -välineisiin, fyysiseen työympäristöön ja työntekijöihin. (Paaskoski 1988; Paaskoski 1993.)

Viisitoista vuotta myöhemmin kansatieteen väitöskirjani tutkimuskohteena oleva "kansa" oli akateemisen koulutuksen saanut ja johtavassa asemassa työskentelevä ammattiryhmä. Tämän "kansanosan" ammattia ja työtä oli pikemminkin mahdotonta hahmottaa työmenetelmiä, työvälineitä tai työympäristöjä kuvaamalla. Sen sijaan tutkimuskysymykseni muotoutuivat varsin abstraktienkin seikkojen ympärille. Mitä on metsänhoitajuus? Miten ammattiryhmään sosiaalistutaan? Miten sosiaalisissa verkostoissa jaetaan yhteisiä kokemuksia ja muistoja? Miten ja miksi niissä ylläpidetään yhteisyyttä?

Oman oppiaineeni määritelmä olikin kuluneen vuosikymmenen aikana merkittävästi muuttunut. Itse asiassa varsinaista määritelmää ei oikein enää tunnu olevan. Sen sijaan uusille opiskelijoille kerrotaan, miten kansatiede on jännittävä tiede juuri siksi, ettei kukaan ole sitä aukottomasti pystynyt määrittelemään. Tieteenalan jokaisen noviisin tulee omakohtaisesti etsiä ja epäröidä - ja viime kädessä jäädä epävarmuuteen kansatieteen ymmärtämisen suhteen. (Helsingin yliopisto, kansatiede [online].) 2000-luvun kansatieteessä akateemisen ammattikulttuurin abstraktien ulottuvuuksien tutkimuskaan ei siten ole mitenkään radikaalia. Tieteenala on tutkimusaiheidensa ja -aineistojensa osalta varsin avaramielinen ja kaikkiruokainen.

Siitä huolimatta noviisi kansatieteellisen tutkimuksen parissa työskennellessään oppii heimostaan jotakin olennaista. Voidakseen olla heimonsa jäsen hänen on tunnistettava oma kulttuurinsa, oman tieteellisen kotinsa "mikroilmasto" (Löfgren 2003, 14), ja toisaalta sen rajat naapurikulttuureihin. Mistä kansatieteilijä tunnistaa kansatieteen, jos sen määrittely on niin vaikeaa? Mitä tarkoittaa kansatieteellinen näkökulma? Ruotsalainen etnologi Orvar Löfgren on kirjoittanut, että kansatieteellä on ikään kuin ominaishaju, ominaismaku tai ominaisväri, jotka kansatieteilijä - sosiaalistuttuaan ensin omaan oppiaineeseensa - tunnistaa (Löfgren 2003, 13-15). Jokin tutkimusaiheessa tai -näkökulmassa siis haiskahtaa kansatieteeltä. Tällaista tuttuuden tunnetta voivat etnologi Lena Gerholmin mukaan vahvistaa esimerkiksi erilaiset tieteenalan avainsymbolit kuten vaikkapa käsitteet kenttätyö, arki, kokemus, kulttuuri. Ymmärrettyäni omassa tutkimuksessani metsänhoitajuuden siksi, mitä metsänhoitajat tekevät tai mistä he kertovat, lienee yhtä luontevaa ja perusteltua ymmärtää kansatiede siksi, mitä kansatieteilijät tekevät. (Bringéus 1986, 9; Gerholm 1993, 11.) Etnologiaa 


\section{Leena PAASKOSkI}

visioidessaan Lena Gerholm on määritellyt tieteenalaa jopa siksi, mitä sen edustajat kaipaavat, haluavat ja ajattelevat tai missä he ovat hyviä (Gerholm 1993, 11, 19). Siten tutkintovaatimusten ja koulutuksen opillisen sisällön ohella kansatieteilijääkin ohjaa merkittävällä tavalla oman oppiaineen hiljainen - ja myös hiljaa muuttuva tieto.

\section{LATTEUDEN ONGELMA}

Kansatieteellä on ollut pitkä perinne menneiden, kadonneiden tai katoamassa olevien ilmiöiden tutkimuksessa ja dokumentoinnissa (ks. esim. Lönnqvist 1990, 23; Rosengren 1991, 29). Katoava kansankulttuuri asetti haasteita tutkimukselle: väitöskirjoissa etsittiin ja kartoitettiin kadonnutta, kerrottiin unohdetusta, ja siten pelastettiin jotakin, mikä ei enää ollut yleisesti tunnettua tai mikä oli ainakin pian vaipumassa unohduksiin. Esimerkiksi E. A. Virtasen vuonna 1950 ja J. Juhani Kortesalmen vuonna 1996 valmistuneet väitöskirjat saivat kumpikin oikeutuksensa katoavan kulttuurin tallennustarpeesta, ensimmäinen itäsuomalaisen kalastuksen, jälkimmäinen vanhan talonpoikaisen poronhoidon osalta. Monien tällaisten kansatieteellisten väitöskirjojen sisällysluettelokin muistuttaa usein museokokoelmien luettelointilomaketta - onhan tutkittavan ilmiön, kuten vaikkapa tuohitöiden, kansanomaisten juomien, haarikkaastioiden, kuistien tai maitolaitureiden tarkka tyypittely, kuvailu ja kartoittaminen edellytys sen tallentamiselle. (Esim. Valonen 1952; Räsänen 1975; Vuoristo 1978; Korhonen 1991; Laamanen 2001.)

Kansatieteen läheinen suhde museotyöhön selittää osin tätä perinnettä (esim. Säs̈kilahti 1999, 148). Museoiden tallentaessa jälkipolville aineellisia todistuskappaleita kansatieteellinen tutkimus on tallentanut niiden kirjallisia kuvauksia. Tällaisten tutkimustulosten arvo kulttuurin tärkeinä tallenteina on ollut itsestään selvä ja vain lisääntynyt ajan kuluessa ja yhteiskunnan muuttuessa. Onkin kiinnostavaa, miten samankaltainen suuntaus näkyi, ei vain kansatieteellisen tutkimuksen vaan myös museotyön näkökulmissa. Vielä 1990-luvun alussa - museoalalle tullessani - tuntui luontevalta tallentaa kulttuuria nimenomaan esineinä, valokuvina tai muina museoobjekteina. Sen sijaan 2000-luvun tallennustyön kohteina museoissa ovat ensisijaisesti ilmiöt, tarinat, kokemukset ja muistot - vaikka niiden aineelliset todistuskappaleet usein ovatkin erilaista materiaa. Myös tämän materian luettelointi on muuttunut: sekin on mieluummin merkityksellisten tarinoiden kuin täsmällisten mittojen kirjaamista. Museoissa tehtävän dokumentoinnin ja kertomisen painopiste on lisäksi yhä useammin lähihistoriassa ja tämän päivän ilmiöissä kuin pelkästään kaukana menneisyydessä.

Myös nykypäivän kansatiedettä kiinnostaa oman kulttuurimme, yhteiskuntamme ja aikamme arkisten ilmiöiden tutkimus. Se tarjoaa varsin toisenlaisia haasteita kuin kadonneen tai katoavan tallennus. Tutkija voi itse jakaa tutkittaviensa käsitykset tutusta, arjesta ja itsestään selvästä, mikä on edellyttänyt kansatieteilijöiltä etäisyyden etsimistä tutkimuskohteeseensa. Juuri arkielämän tavoittamiseen tarvittavaa asennetta on nimitetty myös etnologiseksi asennoitumiseksi (Sääskilahti 1999, 153). Tuttu on pyritty tietoisesti näkemään vieraana, arki ja itsestään selvä erityisenä ja odottamatto- 


\section{KANSATIETEEN HEIMOKULTTUURI}

mana. Toisaalta tuttuudesta on ollut hyötyäkin, sillä kansatieteilijän tutkimusvälineitä ovat voineet olla myös omat kokemukset.

Kun tutkimuskohde on niin tutkijalle kuin tutkimuksen lukijoille omasta elämänpiiristä tuttu ja tutkimushetkellä yhä olemassa ja elinvoimainen, moni tutkija voi etnologi Karl-Olov Arnstbergin tavoin päätyä kuitenkin eräänlaisen latteuden ongelman eteen. Ruotsalaisia sosiaalityöntekijöitä tutkiessaan Arnstberg totesi yrittävänsä sanoa heistä jotakin, mitä ei ennen ole sanottu ja pyrkivänsä tuomaan esiin jotakin uutta jostakin suhteellisen hyvin tunnetusta - kuitenkin siten, että sosiaalityöntekijät tunnistaisivat itsensä tehdystä tutkimuksesta. (Arnstberg 1989, 93.) Kansatieteellisen tutkimuksen paradoksaalinen tehtävä voi siis olla myös kertoa jotakin uutta jostakin kaikille tutusta, arkipäiväisestä, yhä elävästä, ja saada aikaan tutkimustuloksia, jotka eivät ole etukäteen tunnettuja, mutta eivät myöskään tuntemattomia. Itse asiassa on todettukin, että tällainen kansatieteellinen tutkimus onnistuessaan on muun muassa joukko itsestäänselvyyksiä, jotka asianosainen tunnistaa tutkimuksen lukiessaan (Snellman 2003, 8). Lukijan kokema tuttuuden tunne on tae siitä, että tutkija on tehnyt jollakin tapaa oikeita tulkintoja. Mutta mitä on se uusi tieto, jota tällainen tutkimus voi luoda? Mihin tällaista tutkimusta tarvitaan?

Juuri tämän kysymyksen pohtimiseen ja perusteluun tutkijat ovat myös tunteneet tarvetta, kun sinänsä tutun tai yleisesti tunnetun ilmiön kuvailu ja kartoitus eivät tutkimustehtäväksi enää yksin riitä. Kansatieteen tehtävää on usein luonnehdittu näkymättömän näkyväksi tekemiseksi. On ajateltu, että lopultakin juuri oman kulttuurin ja ajan arkiset ja jokapäiväiset seikat jäävät tavanomaisuudessaan ja itsestäänselvyydessään usein huomaamatta; on todettu, että kulttuurin "itsestäänselvyyksien oivaltaminen ja niiden analysoiva ihmettely merkityksellistää merkityksettömän” (Korkiakangas 2006, 125). Laajemminkin kulttuurintutkimuksen kohteena on pidetty yleisesti tiedettyjä, mutta huonosti tiedostettuja asioita (Alasuutari 1999, 234, 237). Itsestäänselvyys ei myöskään aina ole puheenaihe, vaan se voi juuri itsestäänselvyydessään olla vaiettu asia (Ukkonen 2006, 182).

\section{KULTTUURIN KOKONAISKUVA}

Oman kulttuurin ja ajan arkisten, jokapäiväisten ilmiöiden määrittely, analysointi ja tulkinta eivät kuitenkaan ole kansatieteilijöiden tai kulttuurintutkijoiden yksinoikeus. Esimerkiksi väitöskirjatutkimuksessani metsänhoitajat toivat haastatteluissaan esiin paitsi henkilökohtaiset kokemuksensa myös omat tulkintansa niistä. Tutkimusta tehdessäni törmäsin useita kertoja siihen, miten metsänhoitajat elämäkerrallisissa haastatteluissaan kiteyttivät varsin analyyttisesti monia oman ammattinsa ja ammattikulttuurinsa piirteitä - ja esittivät siten ikään kuin samoja tutkimustuloksia, joihin itse olin hetkeä aiemmin monitahoisen aineistoni pohjalta päätynyt.

Tutkijan tehtäväni koin siten usein tulkitsijoiden tulkitsijana ja kertomusten kirjurina toimimiseksi tai tutkittavista metsänhoitajista tuntui ikään kuin muodostuvan kanssatutkijoitani (ks. Pöysä 1997, 18; Salomonsson 1998, 23-25). Vaikka tutkimus- 


\section{LeENA PAASKOSKI}

kohteen oman historian ja sen omien tulkintojen näkyväksi tekeminen voi sinänsä olla tutkimuksen tavoite (Ukkonen 2000, 14), juuri osallistuvan kirjurin tehtävästäni ja itseanalyyttisten metsänhoitajien kuuntelusta seurasi toisinaan latteuden ongelman kasvaminen yhä suuremmaksi. Mitä sellaista olen metsänhoitajista tutkimuksessani sanonut, mitä he eivät jo itse tiedä? Tuoko tutkimukseni metsänhoitajuudesta ylipäätään esiin jotakin sellaista uutta, mitä juuri kansatieteellisen tutkimuksen pitäisi luoda ja mitä juuri kansatieteilijä on hyvä luomaan?

Ilmiön kuvailemisen ja näkyväksi tekemisen ohella tutkijan tavoitteena on usein tutkimuskohteen omien tulkintojen kommentointi, ilmiön selittäminen ja jokin kokonaiskuva (Ukkonen 2000, 14; Kalela 2000, 109). Kulttuuria voi ymmärtää tutkimalla kulttuurin ilmauksia (Arvidsson 2001, 68; Lönnqvist 1999, 32). Sellaisiksi kansatieteilijälle puolestaan kelpaa mikä hyvänsä (esim. Gerholm 1993, 15), suulliset kertomukset, valokuva-albumit, lehtiartikkelit, opiskelijoiden vapaa-ajanviettotavat, kurssilounaiden puheenaiheet, seinäkirjoitukset, jopa takinnapit. Ne ovat kaikki kulttuurin rakennuspalikoita, ehkä erikokoisia ja erimuotoisia, mutta jokaisella yksityiskohdallakin on merkityksellinen paikkansa kokonaisuudessa. Nostamalla esiin tavallisia ja arkipäiväisiä kulttuurin ilmauksia, voi siis ei vain tunnistaa vaan myös liittää asioita toisiinsa, nähdä näiden yhteyksien merkityksiä ja ymmärtää kokonaisuuksia (Lehtonen 2005, 20; Gerholm 1993). Vaikka ilmiön olemassaolo sinänsä olisikin kaikille tuttu ja yleisesti tunnettu, tutkimus voi tarjota sille selityksiä, uusia tulkintoja ja erilaisia perspektiivejä (Alasuutari 1999, 234, 237; Ehn \& Löfgren 1982, 106). Niiden avulla voimme kenties laajemminkin ymmärtää itseämme, kulttuuriamme ja kulttuurisia prosessejamme.

Edellä mainitussa heimo-metaforassaan Oili-Helena Ylijoki korostaa, että vaikka jokainen noviisi omaksuu tieteenalansa traditiot kiinnittyäkseen heimokulttuuriinsa, jokainen tekee sen kuitenkin persoonallisella tavallaan (Ylijoki 2004, 72, 153-154). Tieteenala ja sen tutkimus ovat siten heimojäsentensä ja tutkijoidensa näköisiä. Kansatieteessäkin 1990-luvulta lähtien esitetty vaatimus refleksiivisyydestä, tutkijan oman aseman ja henkilökohtaisten edellytysten, tavoitteiden ja toiveiden tunnustamisesta (Snellman 2003, 56-57; Lehtonen 2005, 20), on korostanut jokaisen tutkimuksen yksilöllisyyttä ja tutkijan ja tutkittavien välisessä vuorovaikutuksessa syntyviä tutkimustuloksia. Kysymyksiin on aina monia vastauksia (Portelli 2005, 72-73).

Kansatieteen tekeminen opettaa tunnistamaan kansatieteellisiä näkökulmia, mutta samalla jokainen tekijä tuottaa heimokulttuurinsa keskuuteen myös uusia aineksia. Kansatieteilijät eivät vain omaksu kansatiedettä, vaan myös toiminnallaan muuttavat sitä: ehkä juuri kansatieteen tutkimuskohteiden ja kansatieteilijöiden liike ja muutos pitävät myös kansatieteellisen näkökulman jatkuvan keskustelun ja määrittelyn kohteena. Käsitys kulttuurista jatkuvana prosessina pätee myös kansatieteilijöiden heimokulttuuriin. 


\section{KANSATIETEEN HEIMOKULTTUURI}

\section{KiRJALLISUUS}

ALASUUTARI, PERTTTI 1999: Laadullinen tutkimus. Tampere: Vastapaino.

ARNSTBERG, KARL-OLOV 1989: Socialarbetare. En etnologisk analys. Lund: Studentlitteratur.

ARVIDSSON, ALF 2001: Etnologi. Perspektiv och forskningsfält. Lund: Studentlitteratur. BRINGÉUS, NILS-ARVID 1986: Människan som kulturvarelse. En introduktion till etnologin. Malmö: Liber.

EHN, BILLY \& LÖFGREN, ORVAR 1982: Kulturanalys. Ett etnologiskt perspektiv. Lund: Liber.

FINGERROOS, OUTI \& HAANPÄÄ, RIINA 2006: Muistitietotutkimuksen ydinkysymyksiä. - Fingerroos, Outi \& Haanpää, Riina \& Heimo, Anne \& Peltonen, Ulla-Maija (toim.), Muistitietotutkimus. Metodologisia kysymyksiä. Helsinki: SKS.

GERHOLM, LENA 1993: Inledning. - Gerholm, Lena (red.), Etnologiska visioner. Femton forskare reflekterar kring sitt ämne. Stockholm: Carlsson.

HELSINGIN YLIOPISTO, kansatiede [online]. < http://www.helsinki.fi/kansatiede/ > [5.4.2008.]

KALELA, JORMA 2000: Historiantutkimus ja historia. Helsinki: Gaudeamus.

KORHONEN, TEPPO 1991: Kuisti. Kansatieteellinen tutkimus. Helsinki: Suomen Muinaismuistoyhdistys.

KORKIAKANGAS, PIRJO 2006: Etnologisia näkökulmia muistiin ja muisteluun. Fingerroos, Outi \& Haanpää, Riina \& Heimo, Anne \& Peltonen, Ulla-Maija (toim.), Muistitietotutkimus. Metodologisia kysymyksiä. Helsinki: SKS.

KORTESALMI, J. JUHANI 1996: Pohjois-Vienan poronhoito. Talonpoikien poronboidon alue, ominaislaatu, ikä, alkuperä ja kehityslinjat vnoteen 1922. Helsinki: Suomen Muinaismuistoyhdistys.

LAAMANEN, JAANA 2001: Maitolaiturilla. Kansatieteellinen tutkimus maitolaitureista ja nïden asemasta suomalaisessa kyläyhteisössä. Helsinki: Kustantajat Sarmala \& Rakennusalan kustantajat RAK.

LEHTONEN, JUHANI U. E. 2005: Kansatieteen tutkimushistoria. - Korkiakangas, Pirjo \& Olsson, Pia \& Ruotsala, Helena (toim.), Polkuja etnologian menetelmiin. Helsinki: Ethnos.

LÖFGREN, ORVAR 2003: Ett ämne väljer väg. - Ehn, Billy \& Löfgren, Orvar, Vardagslivets etnologi. Reflektioner kring en kulturvetenskap. Stockholm: Natur och kultur.

LÖNNQVIST, BO 1990: Remembering and Forgetting. Recording for Posterity. Ethnologia Scandinavica. A Journal for Nordic Ethnology 1990.

LÖNNQVIST, BO 1999: Mitä etnologia on? - Lönnqvist, Bo \& Kiuru, Elina \& Uusitalo, Eeva (toim.), Kulttuurin munttuvat kasvot. Johdatusta etnologiatieteisiin. Helsinki: SKS.

PAASKOSKI, LEENA 1988: Helsinkiläisleipomo vuosisadan alussa. Männynväli 19011921. Proseminaariesitelmä. Julkaisematon. Helsingin yliopisto, kulttuurien tutkimuksen laitos, kansatieteen arkisto.

PAASKOSKI, LEENA 1993: Haapaveden Kotimarjala. Pro gradu -tutkielma. Julkaisematon. Helsingin yliopisto, kulttuurien tutkimuksen laitos, kansatieteen arkisto. 
PORTELLI, ALESSANDRO 2005 (1991): What makes oral history different? - Perks, Robert \& Thomson, Alistair (eds.), The Oral History Reader. London: Routledge.

PÖYSÄ, JYRKI 1997: Jätkän synty. Tutkimus sosiaalisen kategorian muotoutumisesta suomalaisessa kulttuurissa ja itäsuomalaisessa metsätyöperinteessä. Helsinki: SKS.

ROSENGREN, ANNETTE 1991: Två barn och eget hus. Om kvinnors och mäns världar $i$ småsamhället. En etnologisk studie. Stockholm: Carlsson.

RÄSÄNEN, MATTI 1975: Vom Halm zum Fass. Die volkstümlichen alkoholarmen Getreidegetränke in Finnland. Helsinki: Suomen Muinaismuistoyhdistys.

SALOMONSSON, KARIN 1998: Fattigdomens besvärjelser. Visionära ideal och vardagliga realiteter $i$ socialt arbete. Lund: Historiska media.

SNELLMAN, HANNA 2003: Sallan suurin kylä-Göteborg. Tutkimus Ruotsin lappilaisista. Helsinki: SKS.

SÄÄSKILAHTI, NINA 1999: Kansan kulttuurista arkipäivän merkityksiin. - Lönnqvist, Bo \& Kiuru, Elina \& Uusitalo, Eeva (toim.), Kulttuurin munttuvat kasvot. Johdatusta etnologiatieteisiin. Helsinki: SKS.

UKKONEN, TAINA 2000: Menneisyyden tulkinta kertomalla. Muistelupube oman bistorian ja kokemuskertomusten tuottamisprosessina. Helsinki: SKS.

UKKONEN, TAINA 2006: Yhteistyö, vuorovaikutus ja narratiivisuus muistitietotutkimuksessa. - Fingerroos, Outi \& Haanpää, Riina \& Heimo, Anne \& Peltonen, Ulla-Maija (toim.), Muistitietotutkimus. Metodologisia kysymyksiä. Helsinki: SKS.

VALONEN, NIILO 1952: Geflechte und andere Arbeiten aus Birkenrindenstreifen unter besondere Berücksichtigung finnischer Traditionen. Helsinki: Suomen Muinaismuistoyhdistys.

VIRTANEN, E. A. 1950: Itäsuomalaisten kalastusoikeudesta ja -ybtiöistä. Etnososiologinen tutkimus. Helsinki: Suomen Muinaismuistoyhdistys.

VUORISTO, OSMO 1978: Suomalaiset haarikka-astiat. Helsinki: Suomen Muinaismuistoyhdistys.

YLIJOKI, OILI-HELENA 2004: Akateemiset heimokulttuurit ja noviisien sosialisaatio. Tampere: Vastapaino.

Leena Paaskoski 2008: Herrana metsässä. Kansatieteellinen tutkimus metsänhoitajuudesta. Suomalaisen Kirjallisuuden Seuran Toimituksia 1170. Helsinki: Suomalaisen Kirjallisunden Seura.

Filosofian tohtori Leena Paaskoski on intendentti Suomen Metsämuseo Lustossa Punkaharjulla ja sihteeri Metsähistorian Seurassa. 